\title{
Airway smooth muscle as a target of asthma therapy: history and new directions
}

\author{
Luke J Janssen* and Kieran Killian
}

\author{
Address: Firestone Institute for Respiratory Health, St. Joseph's Hospital and the Department of Medicine, McMaster University, Hamilton, \\ Ontario, L8N 3Z5, Canada \\ Email: Luke J Janssen* - janssenl@mcmaster.ca; Kieran Killian - killiank@mcmaster.ca \\ * Corresponding author
}

Published: 29 September 2006

Respiratory Research 2006, 7:123 doi:10.1 186/1465-992I-7-123

This article is available from: http://respiratory-research.com/content/7/I/I23

(c) 2006 Janssen and Killian; licensee BioMed Central Ltd.

This is an Open Access article distributed under the terms of the Creative Commons Attribution License (http://creativecommons.org/licenses/by/2.0), which permits unrestricted use, distribution, and reproduction in any medium, provided the original work is properly cited.
Received: 28 July 2006

Accepted: 29 September 2006

\begin{abstract}
Ultimately, asthma is a disease characterized by constriction of airway smooth muscle (ASM). The earliest approach to the treatment of asthma comprised the use of xanthines and anti-cholinergics with the later introduction of anti-histamines and anti-leukotrienes. Agents directed at ion channels on the smooth muscle membrane $\left(\mathrm{Ca}^{2+}\right.$ channel blockers, $\mathrm{K}^{+}$channel openers) have been tried and found to be ineffective. Functional antagonists, which modulate intracellular signalling pathways within the smooth muscle ( $\beta$-agonists and phosphodiesterase inhibitors), have been used for decades with success, but are not universally effective and patients continue to suffer with exacerbations of asthma using these drugs. During the past several decades, research energies have been directed into developing therapies to treat airway inflammation, but there have been no substantial advances in asthma therapies targeting the ASM. In this manuscript, excitationcontraction coupling in ASM is addressed, highlighting the current treatment of asthma while proposing several new directions that may prove helpful in the management of this disease.
\end{abstract}

\section{Background}

Asthma is experienced during the life span of approximately $10 \%$ of the population, resulting in morbidity and mortality costing a substantial economic burden on society [1]. The predominant feature of asthma is the discomfort experienced upon breathing in the presence of excessive and inappropriate constriction of the airway smooth muscle (ASM). Although airway inflammation may play an important role in asthma, it is benign in the absence of airway narrowing. The patient is thus predominantly concerned with narrowing of their airways, contributing to an unpleasant increase in the effort required to breathe; in the extreme, this increased effort fails to allow sufficient ventilation, leading to morbidity and even mortality. As such, ASM is ultimately a major target in any management of asthma.
The earliest recorded treatments of asthma included tobacco, indian hemp, sedation (using low doses of chloroform, ether, or opium), ipecacuana, coffee, tea, stramonium lobelia and other less effective agents. These agents express the pharmacological properties of the xanthines, cholinergic blockade, sympathetic stimulation, sedation and direct smooth muscle relaxation. Direct approaches using anti-cholinergics, anti-histamines, anti-leukotrienes, and functional antagonists modulating intracellular signalling pathways $(\beta$-agonists and phosphodiesterase inhibitors) followed (section 3.2). These have been used for decades with reasonable success, but patients continue to suffer exacerbations of asthma. Research energies were poured into developing new therapies to treat airway inflammation to prevent rather than treat the active disease. Asthma therapies using immune 
modulation and anti-inflammatory therapies proved to be so successful that targeting the ASM receded. Better understanding of the mechanisms underlying contraction of ASM is still essential to the management of the active disease. In this manuscript, basic excitation-contraction coupling in ASM is summarized and several new directions to the treatment of abnormal smooth muscle constriction are introduced.

\section{Overview of excitation-contraction coupling}

Asthma is characterized by excess reversible constriction and airway hyperresponsiveness (AHR) to a wide variety of spasmogens. Thus, it is essential to understand the mechanisms underlying excitation-contraction coupling of ASM. Contraction is triggered by phosphorylation of myosin. This is catalyzed by $\mathrm{Ca}^{2+} /$ calmodulin-dependent myosin light chain kinase (MLCK), which in turn is activated as $\left[\mathrm{Ca}^{2+}\right]_{\mathrm{i}}$ is elevated (see Fig. 1 ). Mechanisms intrinsic to the thin filament and $\mathrm{Ca}^{2+}$-sensitivity are also involved and have the potential for therapeutic intervention in modulating these basic responses.

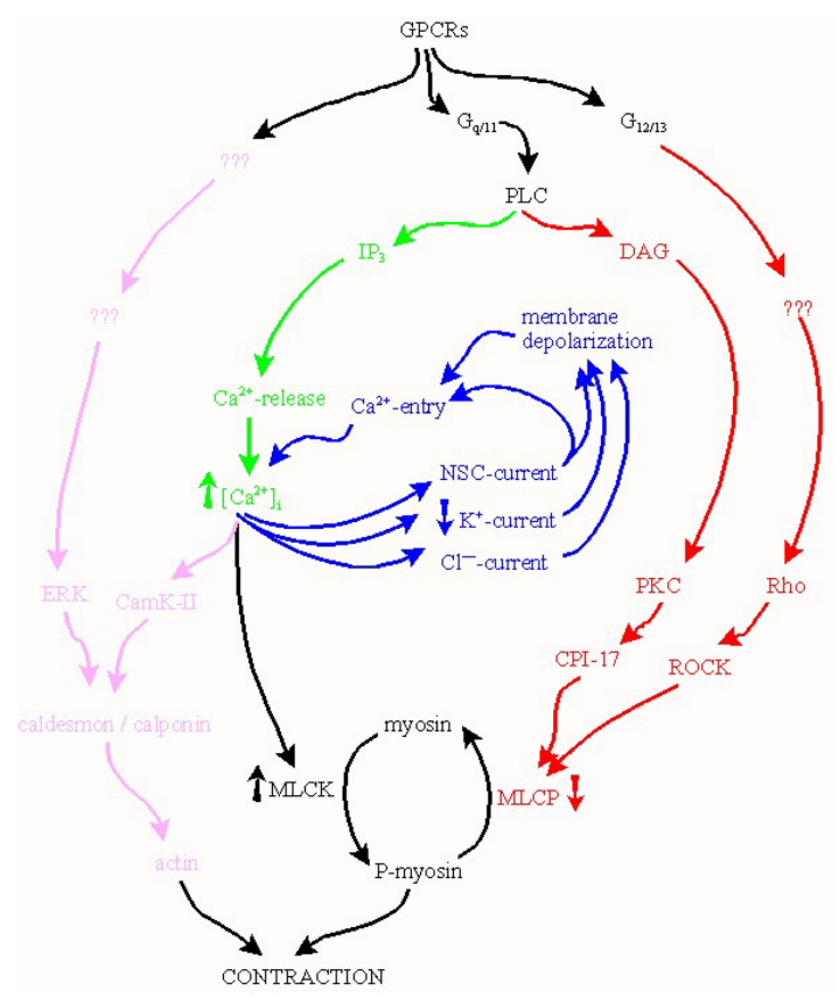

Figure I

Bronchoconstrictors act on G-protein coupled receptors coupled to a variety of signalling pathways involving membrane depolarization (blue), release of internal $\mathrm{Ca}^{2+}$ (green), changes in $\mathrm{Ca}^{2+}$-sensitivity (red), and/or thin filament-mediated mechanisms (magenta).

\section{Voltage-dependent mechanisms}

Excitation-contraction coupling in cardiac, skeletal, vascular and gastrointestinal smooth muscles depends on membrane depolarization resulting in $\mathrm{Ca}^{2+}$-entry via voltage-dependent ('L-type') $\mathrm{Ca}^{2+-}$-channels. As such, $\mathrm{Ca}^{2+}$ channel blockers and $\mathrm{K}^{+}$-channel openers are invaluable in controlling cardiac and smooth muscle contractions in hypertension, stroke, myocardial infarction, gastrointestinal motility disorders, etc. [2-4]. Excitation of ASM is also accompanied by membrane depolarization mediated primarily by $\mathrm{Ca}^{2+}$-dependent $\mathrm{Cl}^{--}$- and non-selective cationchannels, as well as activation of large voltage-dependent $\mathrm{Ca}^{2+}$-currents. The latter can be sufficient to produce contraction, as indicated by the robust responses evoked by potassium chloride or $\mathrm{K}^{+}$-channel blockers. As such, a natural conclusion would be that $\mathrm{Ca}^{2+}$-channel blockers should be useful in the treatment of asthma: however, they are essentially useless in this respect (see section 9.2).

\section{Release of internal $\mathbf{C a}^{2+}$}

Internally sequestered $\mathrm{Ca}^{2+}$ plays an important role in agonist-evoked responses in ASM. The sarcoplasmic reticulum (SR) is central to this, acting as a sink to buffer cytosolic $\left[\mathrm{Ca}^{2+}\right]_{i}$, as well as providing an agonist-releasable store of $\mathrm{Ca}^{2+}$ to trigger contractions. Most, if not all, bronchoconstrictor autacoids act through G-protein-coupled receptors to stimulate phospholipase $\mathrm{C}$ activity and subsequent generation of $\mathrm{IP}_{3}$, which in turn signals the SR to release stored $\mathrm{Ca}^{2+}$ (Fig. 1). The mechanisms underlying $\mathrm{IP}_{3}$ - and ryanodine receptor-mediated release of internal $\mathrm{Ca}^{2+}$ and re-uptake of $\mathrm{Ca}^{2+}$ by the Sarcoplasmic/ Endoplasmic Reticulum $\mathrm{Ca}^{2+}$-ATPase (SERCA) are well understood, although their relative roles in excitationcontraction coupling may not be. Other aspects of $\mathrm{Ca}^{2+}$ handling are very poorly understood, including the mechanism(s) by which the SR is refilled. Greater magnitude of release of $\mathrm{Ca}^{2+}$ in cells/tissues pretreated with allergen or pro-inflammatory cytokines has been documented [5-7]. However, there is little correlation between the magnitude of the initial $\mathrm{Ca}^{2+}$-spike, which lasts only a few seconds, and the subsequent contractile response which lasts many minutes or hours. Other groups [8-13] are now focussing their attention on the frequency of repetitive $\mathrm{Ca}^{2+}$-spikes following agonist stimulation.

\section{Changes in $\mathrm{Ca}^{2+}$-sensitivity}

ASM cells also possess a myosin light chain phosphatase (MLCP) which dephosphorylates myosin, limiting or reversing airway contraction (see Fig. 1). If MLCP activity is down-regulated, net myosin phosphorylation in response to a given change in $\left[\mathrm{Ca}^{2+}\right]_{i}$ will be enhanced and/or prolonged, resulting in greater contraction: in other words, the $\mathrm{Ca}^{2+}$-sensitivity of the contractile apparatus is increased. At least two different signalling pathways have been found to mediate increased $\mathrm{Ca}^{2+}$-sensitivity in 
ASM, the first involving diacylglycerol (another second messenger liberated by phospholipase $\mathrm{C}$ ) and protein kinase C: the latter can phosphorylate CPI-17, which regulates MLCP activity.

The second pathway involves the monomeric G-protein RhoA and its downstream effector molecule Rho-kinase (ROCK). A decade of study in vascular smooth muscle has revealed certain aspects of this signalling cascade (Fig. 2). Inactive RhoA exists in the cytosol with its prenylated hydrophobic tail inserted into its partner molecule, GDP dissociation inhibitor (RhoGDI). G-protein-coupled receptors, upon binding their respective ligands, activate the heterotrimeric G-protein $G_{12,13}$, which in turn triggers one or more tyrosine kinases (c-Src, FAK, Fyn, etc.) and other signalling molecules, culminating in the activation of a Rho-specific guanine nucleotide exchange factor (RhoGEF). Numerous GEFs have been identified in the human genome, but the ones most studied include LARG, PDZ-RhoGEF and p115 RhoGEF. These displace RhoGDI and stimulate exchange of GDP for GTP, activating RhoA, which translocates to the membrane and interacts with ROCK. The latter in turn phosphorylates MLCP at two different threonine residues [14] - Thr696 (inhibiting its phosphatase activity) and Thr853 (interfering with its targeting of myosin) - ultimately leading to suppression of MLCP activity. RhoA inactivates by hydrolyzing the GTP bound to it (catalyzed by Rho-GTPase activating protein, or RhoGAP) and re-associating with RhoGDI.

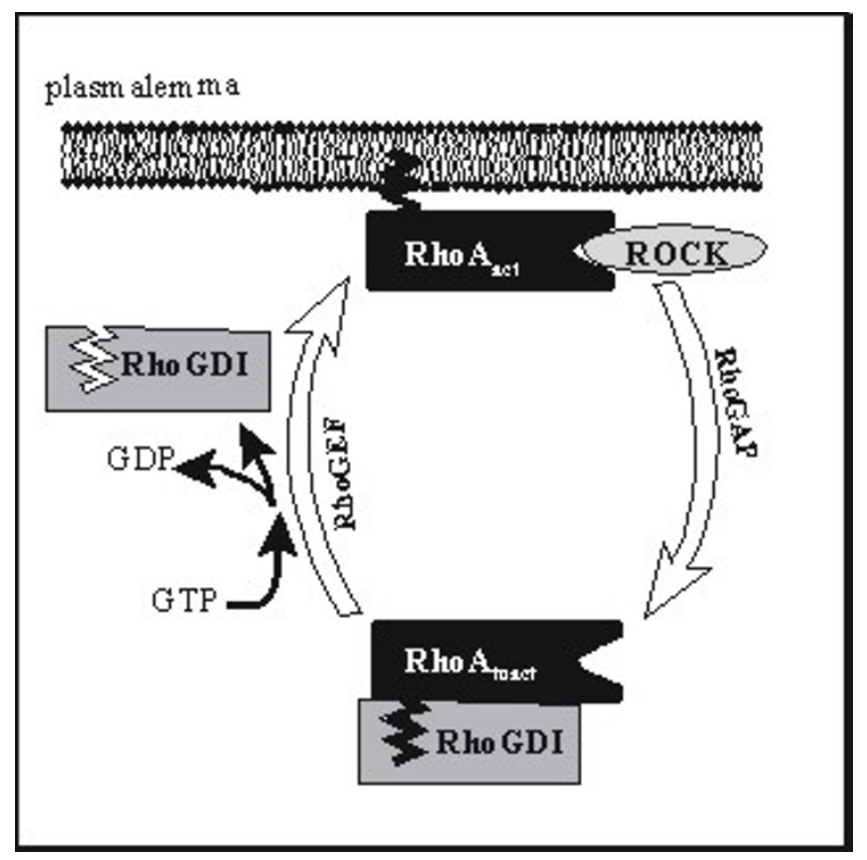

Figure 2

Summary of Rho/ROCK signalling cascade.
Much of the data summarized above were derived from vascular smooth muscle, which may not be applicable to ASM. There are many examples of how these two tissue types can operate quite differently. For example, the two differ dramatically with respect to the role of $\mathrm{Ca}^{2+} / \mathrm{cal}-$ modulin-dependent protein kinase II in activation of RhoA [15]. Likewise, both airway and vascular smooth muscle have exactly the same cellular machinery for voltage-dependent contractions, but have diametrically opposite dependence upon that pathway. Very little is known about the regulation of the Rho/ROCK signalling pathway in ASM, but its exploration may provide novel targets for therapeutic intervention.

\section{Thin filament-mediated mechanisms}

All of the signalling mechanisms summarized above are directed in one way or another at phosphorylation/ dephosphorylation of myosin (i.e., the "thick filament"). Emerging data now also point to a number of mechanisms pertaining specifically to actin (the "thin filament") [16]. In particular, calponin and caldesmon both interact with F-actin and myosin and inhibit actomyosin ATPase activity. Both are regulated by adrenoceptor-stimulated PKC- and ERK-activities: the latter mediate changes in the phosphorylation state and/or localization of caldesmon and calponin, leading to removal of inhibition of actin, resulting in contraction.

\section{Evolution of asthma therapy}

By and large, the advances made in our understanding of excitation-contraction coupling in ASM have been driven largely from other fields, first in skeletal muscle and later vascular smooth muscle, neither of which are good models for ASM physiology (since their physiology is quite different from that of ASM).

\section{Basic pharmacology of excitation of ASM}

Knowledge of the innervations of the airway and the response of ASM to circulating hormones initiated current therapies. The excitatory innervation of ASM is parasympathetic, exerting its actions primarily through muscarinic cholinergic receptors $[17 ; 18]$. Cholinergic receptor blockers progressed from belladonna and stramonium lobeline, leading eventually to atropine. Atropine had substantial side effects, given its pleiotropic effects throughout the body. The inhaled route was exploited to direct treatment to the airway but absorption into the circulation led to distal side effects. Ipratropium bromide, not readily absorbed into the bloodstream, eliminated the major side effects, and is an effective bronchodilator. Anticholinergics, including ipratropium and its long-acting equivalent tiotropium, have been used to treat asthma but in general adrenergic agents are preferred. Anti-cholinergic agents are used with acute severe asthma but are not broadly used in the day-to-day management of mild to 
moderate asthma. More selective drugs may prove more useful (e.g., $\mathrm{M}_{2}$ - and $\mathrm{M}_{3}$-selective blockers).

Sympathetic stimulation relaxes ASM. The finding that the effects of sympathetic stimulation were mimicked by adrenalin (discovered at the turn of the last millenium) and noradrenalin led to the discovery of chemical neurotransmission. In the 1940's the concept of adrenergic receptor subtypes arose due to the different effects of adrenalin on different tissues. This ultimately led to the discovery of specific agonists causing ASM relaxation $\left(\beta_{2^{-}}\right.$ receptor agonists). Short- and long-acting $\beta$-agonists are now the most widely used bronchodilating agents.

The airways of some species including man exhibit a nonadrenergic, non-cholinergic innervation which make a minor contribution to ASM activity. The agonist for this system is still debated, but may include nitric oxide. As such, nitric oxide may provide a useful target for the treatment of asthma.

Asthma precipitated by allergen exposure in sensitized subjects provides a useful experimental model. Allergen binds to IgE on the surface of mast cells following inhalation leading to the immediate release of histamine, which in turn causes an immediate ("early") bronchoconstrictor response within 10 minutes and lasting approximately 90 minutes. Histamine acts on $\mathrm{H}_{1}$ receptors on the ASM, which in turn are coupled to the same signalling pathways utilized by muscarinic receptors (namely, activation of the phosphoinositide cascade, release of internally sequestered $\mathrm{Ca}^{2+}$ and possibly Rho/ROCK-mediated enhancement of $\mathrm{Ca}^{2+}$-sensitivity). Anti-histamines have been proven to be partially effective in the treatment of asthma [18].

The early response is followed 6-8 hours later by a second more prolonged bronchoconstriction lasting many hours or even days, mediated in part by a "slow-reacting substance of anaphylaxis", or SRSA [19]. Upon further investigation, leukotrienes proved to be the mysterious SRSA, leading to the award of a Nobel Prize [94]. In addition to their actions on various inflammatory cells (largely mediated by $\mathrm{LTB}_{4}$ ), leukotrienes act on cys-LT 1 receptors on the ASM: the latter are also G-protein-coupled receptors and, once again, act through stimulation of the phosphoinositide signalling cascade and of the Rho/ROCK-mediated change in $\mathrm{Ca}^{2+}$-sensitivity. This led to the development of blockers of those receptors and of leukotriene synthesis (lipoxygenase inhibitors). The efficacy of these agents in the treatment of asthma has been less than that initially expected but these compounds are widely used.

\section{Functional antagonism of a "convergent signalling pathway" in ASM}

Ironically, the disappointing results of the therapeutic strategies summarized above appear to be due in part to the exceptional pharmacological selectivity of the agents being used. The airways receive numerous excitatory inputs, each acting exclusively on its own distinct plasmalemmal receptor (Fig. 3), and asthma is accompanied by non-specific AHR to a wide variety of excitatory stimuli. As such, an approach which interrupts the intracellular signalling pathways used by many/all of the excitatory stimuli is an exciting prospect.

It was hoped that one such common pathway was voltagedependent $\mathrm{Ca}^{2+}$-influx. The latter is of central importance in cardiac, skeletal, vascular and gastrointestinal muscles, and $\mathrm{Ca}^{2+}$-channel blockers are highly useful in many diseases of those tissues $[20,21]$. There are many lines of evidence which suggest voltage-dependent $\mathrm{Ca}^{2+}$-influx should also be important in ASM, including the depolarizing influence of bronchoconstrictors, the hyperpolarizing influence of bronchodilators, the abundance of the very same type of $\mathrm{Ca}^{2+}$-channel as is present in the nonairway muscles listed above, and the substantial contractions evoked in ASM by high millimolar potassium chloride. It was natural, then, to believe that asthma might also be treated using $\mathrm{Ca}^{2+}$-channel blockers: however, this approach has proven to be useless [22-28]. Despite this setback, others went on to test the potential efficacy of $\mathrm{K}^{+}$channel openers in the treatment of asthma, even though the underlying rationale for such an approach is identical to that of using $\mathrm{Ca}^{2+}$-channel blockers (i.e, to hyperpolarize the membrane such that $\mathrm{Ca}^{2+}$-channels are deactivated). Not surprisingly, this approach was also found to be completely ineffective [29-32]. These and many other findings accumulated over decades of research are most simply interpreted as indicating that voltage-dependent $\mathrm{Ca}^{2+}$-influx is not centrally important in ASM contraction and asthma. Nonetheless, even today there still appears to be a tacit adherence to the dogma that such electromechanical coupling is important. A better understanding of contraction/relaxation in ASM demands a new emphasis on mechanisms which are independent of membrane potential (see below).

Another major line of research focussed on those stimuli which exert an inhibitory (i.e., relaxant) influence on the ASM. The predominant inhibitory innervation is adrenergic in nature, with the neurotransmitter norepinephrine and circulating catecholamines (particularly epinephrine) acting on $\beta$-adrenoceptors (more specifically $\beta_{2}$-subtype in human and many other species). Binding of these ligands to the $\beta_{2}$-receptors leads to stimulation of adenylate cyclase, production of cAMP and consequent increase in protein kinase A activity, which in turn mediates many 


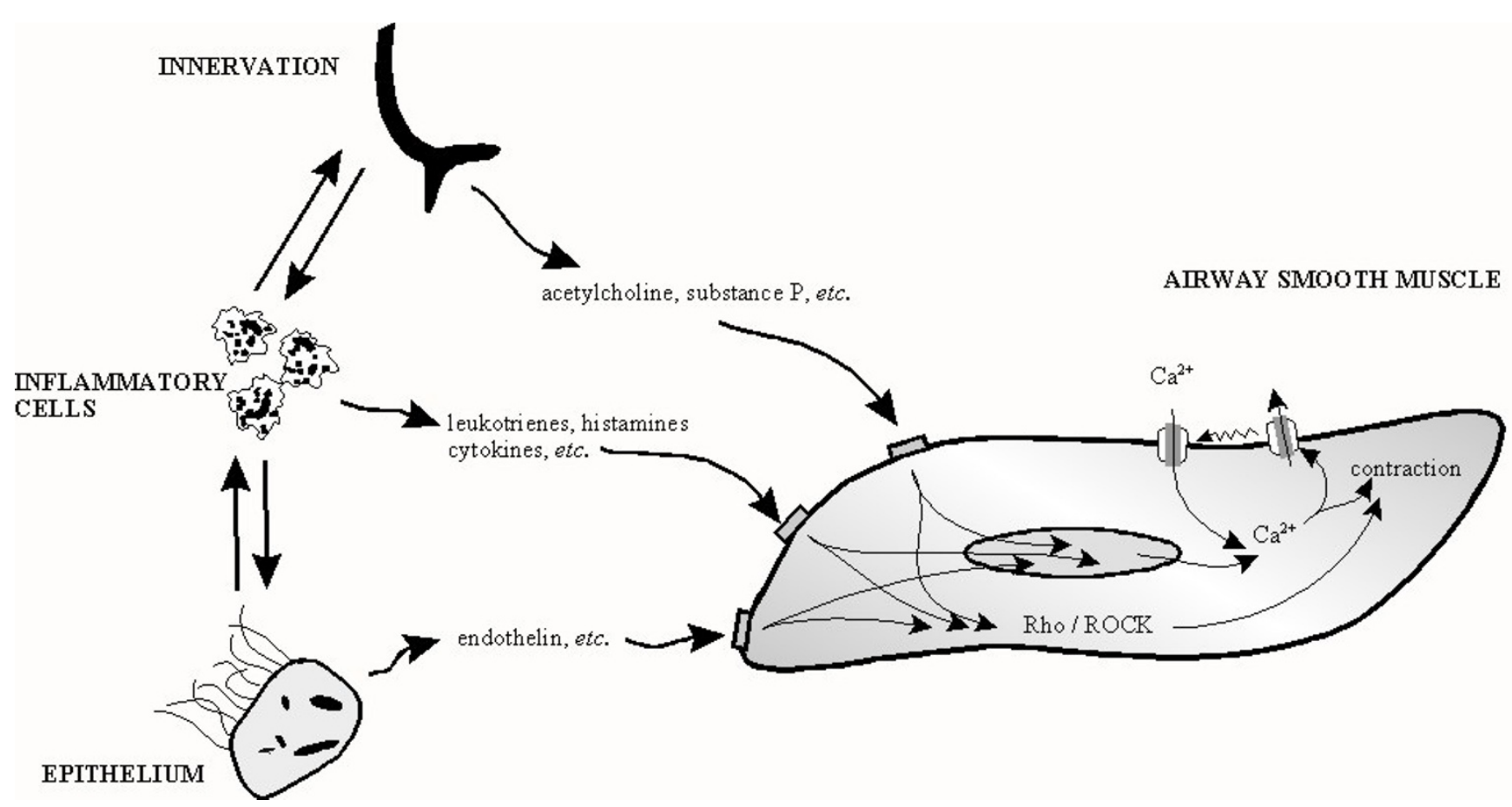

Figure 3

The non-specific nature of airway hyperreactivity and a convergent signalling pathway for spasmogens: hope for a novel therapy for asthma? ASM receives diverse excitatory inputs from the innervation, inflammatory cells, and the epithelium, all of which act through distinct receptors, but a common signalling pathway. In asthma, the smooth muscle exhibits increased sensitivity to a wide range of excitatory stimuli. The non-specific nature of airway hyperreactivity suggests that some post-receptor mechanism(s) within the smooth muscle per se is altered. Spasmogens act through a convergent signalling pathway involving $\mathrm{Ca}^{2+}$-handling and RhoA.

changes that are opposite to those exerted by the bronchoconstrictor agents: vis-a-vis, decreased cytosolic levels of $\mathrm{Ca}^{2+}$ (through a variety of actions on plasmalemmal $\mathrm{K}^{+-}$ and $\mathrm{Ca}^{2+-}$-channels [33], as well as the $\mathrm{Ca}^{2+}$-pumps on the plasmalemma and the SR [34]), inhibition of the RhoA/ ROCK signalling pathway [35] and direct stimulation of MLCP [34]. A more recent development which builds on the knowledge of the actions of CAMP on ASM has been the application of phosphodiesterase inhibitors in the treatment of asthma. These suppress the hydrolysis of CAMP, allowing greater and more prolonged actions upon adrenergic stimulation.

\section{Anti-inflammatory agents}

Given that many of the manifestations of asthma are triggered directly or indirectly by inflammation, asthma treatment is closely allied with immunology. The strategy of interfering with the inflammatory response using an ever longer list of corticosteroids, inhibitors of leukotriene synthesis or leukotriene receptors, blockers of IgE receptors, or of cytokines has been undoubtedly successful. The past decade or two has witnessed a massive research effort to better understand the inflammatory response, with immense resources and energies being directed at identi- fying newer anti-inflammatory agents. A full description of this body of research is beyond the scope of this communication. Prevention of asthma through these strategies is important but treatment of the acute bronchoconstriction will always be required. "If airway inflammation didn't cause acute bronchoconstriction, asthma might be a more tolerable disease" [36]. The most effective strategy to acutely dilate an airway will always be predicated on understanding the process of excitationcontraction coupling (above) and exploiting those mechanisms. An increasingly familiar experience is inadequate treatment of the airflow limitation associated with asthma.

\section{Novel directions}

Despite all the advances summarized above, and the pharmacological interventions which have arisen from them, it still remains that asthma is not well controlled in many individuals. Clearly, different approaches need to be developed. Acetylcholine, histamine and leukotrienes all act through a convergent signalling pathway (Fig. 3): the same is true for other spasmogens such as endothelin, serotonin, substance $\mathrm{P}$, etc.. Appreciation of this fact allows for several potential novel targets to be explored. 


\section{Release of internal $\mathrm{Ca}^{2+}$}

All of the bronchoconstrictor stimuli referred to above act through G-protein-coupled receptors to stimulate $\mathrm{Ca}^{2+}$ release. In contrast to the relative impotence of blockers of voltage-dependent $\mathrm{Ca}^{2+-i n f l u x, ~ a ~ l o n g ~ a n d ~ e v e r-g r o w i n g ~}$ list of in vitro studies of isolated airway tissues attests to the much greater effect of inhibiting $\mathrm{IP}_{3}$-induced $\mathrm{Ca}^{2+}$ release or of depleting the SR using blockers of SERCA. A major drawback is that this $\mathrm{Ca}^{2+}$-homeostatic pathway is central in nearly every cell type in the body, and therefore seems to fail to offer a sufficiently selective target. However, the same criticism can be levelled at many of the other therapeutic approaches which have already been tried (e.g., targeting CAMP). It may be possible to identify components of the $\mathrm{Ca}^{2+}$-homeostatic pathway which are specific to ASM, and/or to limit delivery of agents by having patients inhale modulators of this pathway.

Recently, a great deal of attention has been focussed on the mechanisms underlying refilling of the SR. In many cells, depletion of the internal $\mathrm{Ca}^{2+}$-store triggers a $\mathrm{Ca}^{2+}$ influx pathway. We have begun to characterize a membrane current which is evoked in ASM by depletion of the SR using the SERCA inhibitor cyclopiazonic acid [37]. This current exhibits many electrophysiological and pharmacological properties in common with $\mathrm{Ca}^{2+}$ store depletion-activated currents in other cell types referred to as TRP (Transient Receptor Potential) currents [38,39]. Surprisingly, several recent reviews [38,40,41] have highlighted the potential of TRP-channels as therapeutic targets in ASM, despite the fact that there had not yet been any direct electrophysiological data pertaining to TRP currents in ASM: up to that point, the supporting data for these currents had been obtained exclusively from studies using fluorimetric $\mathrm{Ca}^{2+}$-dyes (which poorly discriminate $\mathrm{Ca}^{2+}$-influx pathways) or very indirect approaches based on mechanical responses as indices of $\mathrm{Ca}^{2+}$-handling. In both cases, the studies have relied on the dubious selectivities of a variety of pharmacological tools.

Several groups including our own have published data which suggest voltage-dependent $\mathrm{Ca}^{2+}$-channels may also contribute to refilling and maintenance of the SR [42-47]. More surprisingly, our data suggest that this refilling pathway in ASM does not involve SERCA, but some novel interaction of the SR and the plasmalemma which allows $\mathrm{Ca}^{2+}$ to flow directly from the extracellular space into the SR $[42,43]$. Elsewhere, a model has been proposed which describes one such interaction [48-53]. Briefly, agonistinduced depletion of the internal store triggers activation of protein tyrosine kinases and Ras: these cause the cytoskeleton to re-organize in such a way as to directly couple $\mathrm{IP}_{3}$-receptors on the SR with $\mathrm{Ca}^{2+}$-channels on the plasmalemma. Several observations made in ASM are consistent with such a mechanism: (i) spasmogenic stim- ulation of ASM is accompanied by activation of tyrosine kinases [54-56] and Ras/Rho [57-60], as well as cytoskeletal rearrangement [55,59-61]; (ii) tyrosine kinase inhibition compromises SR refilling [62]; (iii) ASM depleted of FAK (which regulates cytoskeleton stability) shows marked suppression of cholinergic $\mathrm{Ca}^{2+}$-transients and contractions as well as changes in voltage-dependent $\mathrm{Ca}^{2+}$-channel function, without any disruptive changes in the contractile apparatus per se (assessed by addition of $\mathrm{Ca}^{2+}$ to permeabilized strips) [63]. However, the possible role for this novel SR refilling pathway has not yet been tested in ASM: its presence and operation in ASM would supply another potential target for the treatment of asthma.

Other groups are calling attention to the temporal dynamics of $\mathrm{Ca}^{2+}$-signalling rather than merely the amplitude of the $\mathrm{Ca}^{2+}$-responses. That is, they show that excitatory stimuli do not simply trigger a solitary rise and fall of $\left[\mathrm{Ca}^{2+}\right]_{i^{\prime}}$ but rather a series of repetitive $\mathrm{Ca}^{2+}$ "spikes" or "waves". More importantly, their data indicate that the strength of the contractile response evoked by a bronchoconstrictor depends not so much on the absolute peak magnitude of the $\mathrm{Ca}^{2+}$-elevation, but rather the frequency of the $\mathrm{Ca}^{2+}$ waves $[64,65]$. As such, it may soon prove possible to modulate airway constriction using agents which modulate $\mathrm{Ca}^{2+}$-wave frequency. That is, rather than merely blocking the channels which release internally sequestered $\mathrm{Ca}^{2+}$ from the SR, it may be possible to modulate the kinetics of their activation, thereby affecting the onset of each $\mathrm{Ca}^{2+}$-spike. Alternatively, the cellular effectors which determine the decay or resolution of each $\mathrm{Ca}^{2+}$-spike may offer useful targets: these include the $\mathrm{Ca}^{2+}$-release channels themselves (perhaps it might be possible to accelerate their deactivation or inactivation), as well as the cellular entities which restore $\left[\mathrm{Ca}^{2+}\right]_{i}$ to resting levels (the plasmalemmal $\mathrm{Ca}^{2+}$-pump, SERCA and $\mathrm{Na}^{+} / \mathrm{Ca}^{2+}$ exchange).

\section{Cl--channels}

ASM exhibits large $\mathrm{Cl}^{-}$currents in response to excitatory stimuli, and these are tightly regulated by second messenger signalling events [66-72]. It is usually concluded that $\mathrm{Cl}^{--}$currents are important for excitation-contraction coupling by depolarizing the membrane and thus triggering voltage-dependent $\mathrm{Ca}^{2+}$-influx, and would for this reason provide a potential target for asthma therapy. However, this therapeutic approach should be no more effective than suppressing voltage-dependent $\mathrm{Ca}^{2+}$-influx using $\mathrm{Ca}^{2+}$-channel blockers or $\mathrm{K}^{+}$-channel openers (neither of which have proven to be effective). Why, then, are $\mathrm{Cl}^{--}$channels so prominent in ASM?

A Cl---channel has been isolated from ASM with properties similar to those on the SR of skeletal and cardiac muscle where they facilitate $\mathrm{Ca}^{2+}-$ flux by neutralizing charge 
build-up on the SR membranes [73]. We have therefore proposed an entirely novel and testable hypothesis [74]: that agonists activate $\mathrm{Cl}^{--}$currents in ASM in order to facilitate $\mathrm{Ca}^{2+}$-release/uptake. That is, $\mathrm{Ca}^{2+}$-efflux from the SR leads to a net negative charge on the inner face of the SR membrane which hinders $\mathrm{Ca}^{2+}{ }^{2}$-release unless alleviated by compensatory fluxes of $\mathrm{Cl}^{-}$out of the SR. Given that the agonists trigger substantial plasmalemmal $\mathrm{Cl}^{--}$currents, the sudden loss of $\mathrm{Cl}^{--}$from the subplasmalemmal space would instantaneously alter the equilibrium potential for $\mathrm{Cl}^{-}$across the SR membrane, thereby facilitating efflux of $\mathrm{Cl}^{--}\left(\right.$and $\left.\mathrm{Ca}^{2+}\right)$ from the SR. Consistent with this, we found contractions evoked by various stimuli including caffeine to be reduced by removing external $\mathrm{Cl}^{--}[75]$; interestingly, reintroduction of $\mathrm{Cl}^{-}$restored the initial peak response, suggesting normal refilling of the SR.

Cytosolic [ $\left.\mathrm{Cl}^{-}\right]$may also modulate RhoA/ROCK signalling in ASM. While characterizing the agonist-evoked $\mathrm{Cl}^{--}$currents in canine ASM, we noted contractions could be evoked repeatedly during voltage clamp at $-60 \mathrm{mV}$ (at which voltage-dependent $\mathrm{Ca}^{2+}$-channels are not open) and in the presence of cyclopiazonic acid [43]: such contractions are clearly independent of both voltage-dependent $\mathrm{Ca}^{2+}$-influx and release of internal $\mathrm{Ca}^{2+}$ and therefore likely involve altered $\mathrm{Ca}^{2+}$-sensitivity of the contractile apparatus. More importantly, we found that cells which were perfused internally with a $\mathrm{Cl}^{-}$-deficient electrode solution quickly lost the ability to contract [70]. One interpretation of these findings is that $\mathrm{Cl}^{--}$is somehow essential to Rho and/or ROCK activation. Consistent with that, we have found that the $\mathrm{Cl}^{--}$-channel blocker niflumic acid markedly suppresses cholinergically-induced RhoAactivation. Changes in subplasmalemmal $\left[\mathrm{Cl}^{-}\right]$might facilitate translocation of RhoA to the membrane, or enhance interactions between the different components of this signalling cascade. Others have shown G-protein activity to be modulated by [Cl--] [76]. Alternatively, it might be possible that changes in cytosolic [Cl--] somehow affect ROCK activation and/or kinetics.

\section{RhoA/ROCK signalling}

An ever growing literature attests to the importance of the RhoA/ROCK signalling pathway in increased $\mathrm{Ca}^{2+}$-sensitivity of smooth muscle in general. ROCK inhibitors are effective as bronchodilators [35,77-79]. Increased RhoA/ ROCK activities have been documented in allergic models of asthma [80-86]. However, little is known about the details underlying activation and modulation of this signalling pathway in ASM. Work done in vascular smooth muscle, or even non-muscle preparations, may not be equally applicable in ASM, as exemplified in the great deal of time and effort spent, and lost, on studying voltagedependent $\mathrm{Ca}^{2+}$-influx in ASM. Also, although many have examined stimulation of the RhoA/ROCK signalling path- way by excitatory agonists $[77,79,87-90]$, very few have looked at the effects of relaxant agonists on this pathway. Recently, we were the first to measure directly the activities of RhoA and ROCK in ASM using immunoprecipitation pull-down and radiometric enzyme assays [15,35,88], and so documented the kinetics of activation of these two signalling molecules: RhoA becomes activated within seconds, reaching a peak within 2 minutes, but then falls back toward baseline even though tone continues to build. We also described the inhibitory effects, particularly on ROCK activity, of two different $\beta$-agonists - isoproterenol (a short-acting, non-selective $\beta$-agonist with full agonist activity) and salmeterol (a long-acting, $\beta_{2^{-}}$ selective agonist with only partial agonist activity), both of which signal through stimulation of adenylate cyclase activity - and a nitric oxide donor (S-nitroso-N-acetylpenicillamine; acting through stimulation of guanylate cyclase).

Many of the details underlying RhoA/ROCK activation remain to be explored. We were the first to show in ASM that RhoA is activated by potassium chloride [88]. Follow up work showed that this is directly related to elevated $\left[\mathrm{Ca}^{2+}\right]_{\mathrm{i}^{\prime}}$ although membrane depolarization per se may also be involved. Changes in ROCK activity parallelled those in RhoA, suggesting $\mathrm{KCl}$ is not exerting an additional effect on ROCK (i.e., is only stimulating RhoA). How might $\mathrm{Ca}^{2+}$ and membrane voltage stimulate RhoA activity? It may be that Rho-activation is $\mathrm{Ca}^{2+}$-dependent, although this explanation must explain the relative inefficacy of $\mathrm{Ca}^{2+}$-channel blockers. Alternatively, proteins are charged molecules, and those which need to translocate to the membrane must by influenced by the transmembrane voltage gradient. On the other hand, there is a growing literature describing direct physical interactions between various enzymes and ion channels, including "L-type" $\mathrm{Ca}^{2+-}$-channels $[91,92]$. It is possible that depolarizationinduced conformational changes in the channel proteins are transduced to accessory cytosolic proteins including RhoA; $\mathrm{Ca}^{2+}$-channel blockers do not necessarily affect those conformational changes, which could explain why ASM is refractory to that class of drug. None of these possibilities have been explored sufficiently.

Finally, the downstream targets which ROCK must phosphorylate to evoke contraction have not been examined in detail. MLCP may be the primary target [93]. However, data from non-airway tissues suggest that ROCK also phosphorylates myosin light chain per se [94,95], ezrin/ radixin/moesin family proteins [96-99], elongation factor- $1 \alpha[100]$, adducin $[99,101]$, intermediate filaments [102-104], and LIM-kinase $[105,106]$. There likely are other targets which have not yet been revealed. 
HMG-CoA reductase inhibitors or 'statins' are widely used to normalize hypercholesterolemia [107]. However, it is now becoming clear that their beneficial effects may not only lie in their ability to decrease cholesterol synthesis per se [108]. Geranylgeranylpyrophosphate, an isoprenoid intermediate arising from this biosynthetic pathway, is essential in the activation of RhoA. As such, statins may also act by suppressing Rho/ROCK signalling, a pharmacological action which might be exploited in asthma.

\section{Tyrosine kinase(s)}

We have shown the non-specific tyrosine kinase inhibitor genistein to have powerful inhibitory effects on cholinergic responses in ASM [89]. However, the identity of the tyrosine kinase(s) and the target(s) of its stimulation are largely unclear. There is currently a great deal of attention being focussed upon the role(s) of FAK in cholinergic responses in ASM [109-111]: upon stimulation, FAK can be autophosphorylated on tyrosine 397, recruiting other non-receptor PTKs such as pp60 $0^{\text {src }}$ and pp5 5 fyn $^{\text {(via their }}$ SH2 domains), which can create additional tyrosine phosphorylation on other residues of FAK. Also, there is reason to believe that tyrosine phosphorylation is part of the RhoA signalling pathway (leading to activation of RhoGEF) as well as to $\mathrm{Ca}^{2+}$-handling in ASM [54]. Thus, tyrosine kinase inhibitors could prove valuable in the treatment of asthma, if a sufficiently selective molecule can be found.

\section{Actomyosin ATPase activity and cross-bridge cycling}

Rather than interfering with various "up-stream" signalling events, it could be much more effective to target the penultimate step in excitation-contraction coupling. Activation of actomyosin ATPase activity, through the phosphorylation of myosin light chain, and cross-bridge cycling are the final determinants in the overall cascade of events leading to contraction. A direct inhibitor of MLCK could be far more effective than intervening further upstream using $\beta$-agonists and phosphodiesterase inhibitors. On the other hand, MLCP offers a tantalizing target: the identification of a compound which directly, and hopefully selectively, stimulates this activity would be equally effective in the treatment of asthma. In contrast to the extensive literature at hand pertaining to kinases and the availability of innumerable "selective" kinase inhibitors, the phosphatase field is still in its infancy: relatively few selective inhibitors are yet available, perhaps in part because the actual catalytic subunit of these enzymes acts non-selectively on a wide variety of substrates but is brought into proximity of a specific substrate by the targeting subunit. As such, perhaps the targeting subunit should itself be targeted by researchers. Clearly, any putative MLCK inhibitors or MLCP stimulants to be developed for use in asthma would have to contend with the issue of unwanted systemic effects, given the importance of these enzymes in a wide variety of processes and cell types. However, as pointed out above, it may be possible to limit the systemic delivery of any trial compounds by developing them as inhaled agents and/or using gene therapeutic approaches.

The so-called thick filament-mediated mechanisms those centering around myosin - have eclipsed research in ASM excitation-contraction coupling in large part, and the development of anti-asthma therapies in total. The growing understanding of the importance of thin filamentmediated mechanisms in smooth muscle contraction may eventually reveal other therapeutic approaches for dealing with airway bronchospasm.

\section{Approaches designed to decrease ASM mass per se}

A radically different approach would be to ablate the ASM itself, rather than modulate its activity. The question of "why do we have airway smooth muscle" has been raised repeatedly in the past with no convincing and satisfying answers yet (this question is deftly reviewed in ref. [112]). An exciting new development in this arena has been the controlled delivery of thermal energy to the airways using an intrabronchial catheter: a process now referred to as bronchial thermoplasty $[113,114]$. This technique was originally intended to serve as a treatment for chronic obstructive pulmonary disorder, in which collapse of the airways and gas trapping is a major problem: as such, the thought was that inducing scarring of the airways might make them stiffer and thus remain patent. Instead, no scarring is evident and the airways look completely normal except for the peculiar absence of smooth muscle cells; patients also commented on improved lung function and reduction of symptoms related to asthma. Preclinical development-stage work was done in dogs, and included a long series of studies aimed at determining the intensity and duration of delivery of radiofrequency energy required to achieve $50 \%$ reduction in ASM mass. The procedure was next tested in a small group of mild asthmatics, and is now being tested in a group of moderate-severe asthmatics. The success of this approach underscores the potential value in developing other means to eradicate the ASM, including the smaller airways. It may be possible to develop toxic chemical interventions which could be delivered specifically to the ASM (e.g., via gene therapeutic approaches). Further studies of the cell cycle of ASM are essential, since it may eventually be possible to inhibit ASM proliferation and/or promote ASM apoptosis, both of which would achieve the same desired goal of decreasing overall ASM muscle mass. Likewise, a better understanding of ASM migration could lead to the development of agents which prevent the hypertrophy/hyperplasia which accompany asthma. 


\section{Prospects for the future}

As stated above, there have not been any substantially new pharmacological advances in the past decade or two with respect to treatment strategies for asthma which target the ASM. Admittedly, there have been newer $\beta$-agonists or phosphodiesterase inhibitors, but these represent only modifications of decades-old strategies. Any truly new advances have been aimed at controlling inflammation, which is also important but should not eclipse any efforts aimed at controlling bronchoconstriction directly. We have stated repeatedly that a better understanding of the mechanisms underlying ASM contraction and AHR is a prerequisite for any such new advances, and that it would be unwise to base any such understanding solely on work being done in the vascular smooth muscle field, let alone others studying non-muscle tissues.

Physiological studies have for too long suffered from important design flaws and limitations. First, the vast majority of studies have been done using tracheal smooth muscle rather than the smaller airways which are far more important in determining resistance to airflow and which are the clinically relevant site of airway inflammation: compounding this shortsightedness is the growing body of literature which shows major structural and functional differences between the large and small airways. Also, too many use maximally effective concentrations of excitatory stimuli $-e . g$. , near millimolar concentrations of cholinergic agonists - even though such degrees of stimulation are rarely (if ever) reached in nature; this problem is exacerbated by numerous studies which suggest the relative contributions of various signalling events can vary over the full range of a concentration-response relationship. Mitchell and Sparrow have elegantly shown that only the lower half of the full concentration-response relationship may be relevant, since complete airway closure can occur at roughly the half-maximally effective concentration [115]. As such, any further increase in tension seen at higher concentrations would be completely occult: thus, we need to focus instead on submaximal or even threshold responses. Related to this point, many are now showing that isotonic recordings (in which the muscle shortens as tone develops) capture information which is unavailable or distorted in isometric studies (the mainstay of most studies of ASM physiology and pharmacology). Finally, the bulk of the data pertaining to this matter were obtained under static conditions, whereas very recent work now shows ASM function to be powerfully modulated by mechanical perturbations (stretch; deep inspirations; etc.) [116-118]. It is becoming increasingly clear that this is related to a dynamic re-organization of the actin and myosin filaments during contraction. This adaptation of ASM to its microenvironment ('plasticity') may explain many lung/airway phenomena and offer clues for novel therapeutic intervention.
A major and fundamental limitation in studies aimed at better understanding and treating asthma has been the lack of a good animal model of asthma. Asthma is characterized, in part, by AHR, reversible bronchoconstriction, wheezing, inflammation, and cellular changes related to the muscle (hypertrophy and/or hyperplasia), epithelium (denudation; mucous production), and inflammatory cells (infiltration; degranulation; phenotypic changes). There are many animal models which feature a degree of AHR (e.g., induced by allergens or noxious agents) which may or may not be accompanied by inflammation, or which reproduce many features of airway inflammation without a change in ASM responsiveness. Regarding those studies which do find AHR in an experimental model, this is usually minor compared to that seen in asthmatics: there is generally only a modest increase in the maximal response and a slight leftward shift, compared to the dramatic shift of several log units in the human condition. Animals do not wheeze (although horses can manifest heaves). In summary, there is no animal model which reproduces fully all the features of asthma. Ultimately, our goal should be to better understand excitation-contraction coupling in human ASM, and changes in that coupling should be studied in tissues from asthmatics.

\author{
Abbreviations \\ AHR airway hyperresponsiveness \\ ASM airway smooth muscle \\ MLCK myosin light chain kinase \\ MLCP myosin light chain phosphatase \\ RhoGAP Rho-GTPase activating protein \\ RhoGDI Rho-specific GDP dissociation inhibitor
}

RhoGEF Rho-specific guanine nucleotide exchange factor

ROCK Rho-kinase

SERCA sarcoplasmic/endoplasmic reticulum $\mathrm{Ca}^{2+}$-ATPase

SRSA slow-reacting substance of anaphylaxis

TRP transient receptor potential

\section{Competing interests}

The author(s) declare that they have no competing interests.

\section{References}

I. Fuhlbrigge AL, Adams RJ, Guilbert TW, Grant E, Lozano P, Janson SL, Martinez F, Weiss KB, Weiss ST: The burden of asthma in the United States: level and distribution are dependent on inter- 
pretation of the national asthma education and prevention program guidelines. Am J Respir Crit Care Med 2002, 1 66: 1044-1049.

2. Fleckenstein A, Frey M, Fleckenstein-Grun G: Antihypertensive and arterial anticalcinotic effects of calcium antagonists. American Journal of Cardiology 1986, 57:ID-10D.

3. Faraci FM, Heistad DD: Regulation of the cerebral circulation: role of endothelium and potassium channels. Physiological Reviews 1998, 78:53-97.

4. Quayle JM, Nelson MT, Standen NB: ATP-sensitive and inwardly rectifying potassium channels in smooth muscle. Physiol Rev 1997, 77:1 165-1232.

5. Amrani $Y$, Bronner $C$ : Tumor necrosis factor alpha potentiates the increase in cytosolic free calcium induced by bradykinin in guinea-pig tracheal smooth muscle cells. C R Acad Sci III 1993, 3 | 6: | 1489-1494.

6. Amrani Y, Panettieri RA Jr, Frossard N, Bronner C: Activation of the TNF alpha-p55 receptor induces myocyte proliferation and modulates agonist-evoked calcium transients in cultured human tracheal smooth muscle cells. Am J Respir Cell Mol Biol 1996, 15:55-63.

7. Zacour ME, Tolloczko B, Martin JG: Calcium and growth responses of hyperresponsive airway smooth muscle to different isoforms of platelet-derived growth factor (PDGF). Can J Physiol Pharmacol 2000, 78:867-873.

8. Bergner A, Sanderson MJ: Acetylcholine-induced calcium signaling and contraction of airway smooth muscle cells in lung slices. J Gen Physiol 2002, I I 9: 187-198.

9. Bergner A, Sanderson MJ: ATP stimulates $\mathbf{C a}^{2+}$ oscillations and contraction in airway smooth muscle cells of mouse lung slices. Am J Physiol Lung Cell Mol Physiol 2002, 283:LI27I-LI 279.

10. Kuo KH, Dai J, Seow CY, Lee CH, van Breemen C: Relationship between asynchronous $\mathrm{Ca}^{2+}$ waves and force development in intact smooth muscle bundles of the porcine trachea. Am J Physiol Lung Cell Mol Physiol 2003, 285:LI345-LI353.

II. Nuttle LC, Farley JM: Frequency modulation of acetylcholineinduced oscillations in $\mathrm{Ca}^{2+}$ and $\mathrm{Ca}^{2+}$-activated $\mathrm{Cl}$-current by cAMP in tracheal smooth muscle. J Pharmacol Exp Ther 1996, 277:753-760.

12. Prakash YS, Pabelick CM, Kannan MS, Sieck GC: Spatial and temporal aspects of $A C h$-induced $\left[\mathrm{Ca}^{2+}\right]_{i}$ oscillations in porcine tracheal smooth muscle. Cell Calcium 2000, 27:153-162.

13. Roux E, Guibert C, Savineau JP, Marthan R: $\left[\mathrm{Ca}^{2+}\right]_{i}$ oscillations induced by muscarinic stimulation in airway smooth muscle cells: receptor subtypes and correlation with the mechanical activity. Br J Pharmacol |997, I 20: | 294- I30I.

14. Ratz PH, Berg KM, Urban NH, Miner AS: Regulation of smooth muscle calcium sensitivity: $\mathrm{KCl}$ as a calcium-sensitizing stimulus. Am J Physiol Cell Physiol 2005, 288:C769-C783.

15. Liu C, Zuo J, Pertens E, Helli PB, Janssen L): Regulation of Rho/ ROCK signaling in airway smooth muscle by membrane potential and $\left[\mathrm{Ca}^{2+}\right]_{\mathrm{i}}$. Am J Physiol Lung Cell Mol Physiol 2005.

16. Morgan KG, Gangopadhyay SS: Invited review: cross-bridge regulation by thin filament-associated proteins. J Appl Physiol $200 \mathrm{I}$, 91:953-962.

17. Frank DE, Maclaren WR: The use of an anticholinergic drug in the treatment of asthma. Ann Allergy 1957, I5:26I-269.

18. Silbert NE: Treatment of bronchial conditions with a combination of anticholinergic, adrenergic, and antihistaminic drugs; preliminary report. Ann Allergy 1952, 10:469-472.

19. Brocklehurst WE: The role of slow-reacting substance in asthma. Adv Drug Res 1970, 5:109-II3.

20. Triggle DJ: Calcium, the control of smooth muscle function and bronchial hyperreactivity. Allergy 1983, 38:1-9.

21. Middleton E Jr: Airway smooth muscle, asthma, and calcium ions. J Allergy Clin Immunol 1984, 73:643-650.

22. Barnes $\mathrm{PJ}$ : Clinical studies with calcium antagonists in asthma. $\mathrm{Br} J$ Clin Pharmacol 1985, 20(Suppl 2):289S-298S.

23. Fish JE: Calcium channel antagonists in the treatment of asthma. J Asthma 1984, 21:407-418.

24. Gordon EH, Wong SC, Klaustermeyer WB: Comparison of nifedipine with a new calcium channel blocker, flordipine, in exercise-induced asthma. J Asthma I987, 24:26I-265.

25. Hoppe M, Harman E, Hendeles L: The effect of inhaled gallopamil, a potent calcium channel blocker, on the late-phase response in subjects with allergic asthma. J Allergy Clin Immunol 1992, 89:688-695.

26. Middleton E Jr: The treatment of asthma - beyond bronchodilators. N Engl Reg Allergy Proc 1985, 6:235-237.

27. Riska $H$, Stenius-Aaniala B, arvi AR: Comparison of the efficacy of an ACE-inhibitor and a calcium channel blocker in hypertensive asthmatics. A preliminary report. Postgrad Med J 1986 , 62(Suppl I):52-53

28. Sly PD, Olinsky A, Landau LI: Does nifedipine affect the diurnal variation of asthma in children? Pediatr Pulmonol 1986 2:206-210.

29. Cook NS, Chapman ID: Therapeutic potential of potassium channel openers in peripheral vascular disease and asthma. Cardiovasc Drugs Ther 1993, 7(Suppl 3):555-563.

30. Faurschou P, Mikkelsen KL, Steffensen I, Franke B: The lack of bronchodilator effect and the short-term safety of cumulative single doses of an inhaled potassium channel opener (bimakalim) in adult patients with mild to moderate bronchial asthma. Pulm Pharmacol 1994, 7:293-297.

3I. Kidney JC, Fuller RW, Worsdell YM, Lavender EA, Chung KF, Barnes PJ: Effect of an oral potassium channel activator, BRL 38227, on airway function and responsiveness in asthmatic patients: comparison with oral salbutamol. Thorax 1993, 48:130-133.

32. Small RC, Berry JL, Burka JF, SJ Cook, Foster RW, Green KA, Murray MA: Potassium channel activators and bronchial asthma. Clin Exp Allergy 1992, 22: I I- I8

33. Kotlikoff MI, Kamm KE: Molecular mechanisms of beta-adrenergic relaxation of airway smooth muscle. Annu Rev Physiol 1996, 58:|15-14|

34. Janssen LJ, Tazzeo T, Zuo J: Enhanced myosin phosphatase and $\mathrm{Ca}^{2+}$-uptake mediate adrenergic relaxation of airway smooth muscle. Am J Respir Cell Mol Biol 2004, 30:548-554.

35. Liu C, Zuo J, Janssen LJ: Regulation of airway smooth muscle RhoA/ROCK activities by cholinergic and bronchodilator stimuli. Eur Respir J 2006.

36. Solway J, Forsythe SM, Halayko AJ, Vieira JE, Hershenson MB, Camoretti-Mercado $B$ : Transcriptional regulation of smooth muscle contractile apparatus expression. Am J Respir Crit Care Med 1998, I 58:S100-S108.

37. Helli PB, Pertens E, Janssen LJ: Cyclopiazonic acid activates a $\mathrm{Ca}^{2+}$-permeable, non-selective cation conductance in porcine and bovine tracheal smooth muscle. J Appl Physiol 2005.

38. Li S, Westwick J, Poll C: Transient receptor potential (TRP) channels as potential drug targets in respiratory disease. Cell Calcium 2003, 33:551-558.

39. Montell C: New light on TRP and TRPL. Mol Pharmacol I997, 52:755-763.

40. Gosling M, Poll C, Li S: TRP channels in airway smooth muscle as therapeutic targets. Naunyn Schmiedebergs Arch Pharmacol 2005, 371:277-284.

4I. Ong HL, Barritt GJ: Transient receptor potential and other ion channels as pharmaceutical targets in airway smooth muscle cells. Respirology 2004, 9:448-457.

42. Bourreau JP, Abela AP, Kwan CY, Daniel EE: Acetylcholine $\mathbf{C a}^{2+}$ stores refilling directly involves a dihydropyridine-sensitive channel in dog trachea. Am J Physiol 1991, 26I:C497-C505.

43. Janssen LJ, Sims SM: Emptying and refilling of $\mathrm{Ca}^{2+}$ store in tracheal myocytes as indicated by $A C h$-evoked currents and contraction. Am J Physiol 1993, 265:C877-C886.

44. Qian Y, Bourreau JP: Two distinct pathways for refilling $\mathrm{Ca}^{2+}$ stores in permeabilized bovine trachealis muscle. Life Sci 1999, 64:2049-2059.

45. Bourreau JP, Kwan CY, Daniel EE: Distinct pathways to refill ACh-sensitive internal $\mathrm{Ca}^{2+}$ stores in canine airway smooth muscle. Am J Physiol 1993, 265:C28-C35.

46. Yang CM, Yo YL, Wang YY: Intracellular calcium in canine cultured tracheal smooth muscle cells is regulated by $\mathbf{M}_{3}$ muscarinic receptors. Br J Pharmacol 1993, I I 0:983-988.

47. Liu X, Farley JM: Depletion and refilling of acetylcholine- and caffeine-sensitive $\mathbf{C a}^{2+}$ stores in tracheal myocytes. J Pharmacol Exp Ther 1996, 277:789-795.

48. Rosado JA, Sage SO: The actin cytoskeleton in store-mediated calcium entry. J Physiol 2000, 526(Pt 2):22I-229.

49. Patterson RL, van Rossum DB, Gill DL: Store-operated $\mathbf{C a}^{2+}$ entry: evidence for a secretion-like coupling model. Cell 1999, 98:487-499. 
50. Yao Y, Ferrer-Montiel AV, Montal M, Tsien RY: Activation of store-operated $\mathrm{Ca}^{2+}$ current in $\mathrm{Xenopus} \mathrm{oocytes} \mathrm{requires}$ SNAP-25 but not a diffusible messenger. Cell I 999, 98:475-485

5I. Berridge MJ: Capacitative calcium entry. Biochem J 1995, 3 I 2(Pt I):I-II.

52. Kobayashi S, Gong MC, Somlyo AV, Somlyo AP: $\mathbf{C a}^{2+}$ channel blockers distinguish between $\mathbf{G}$ protein-coupled pharmacomechanical $\mathbf{C a}^{2+}$ release and $\mathbf{C a}^{2+}$ sensitization. Am J Physiol |99|, 260:C364-C370.

53. Rosales C, Brown EJ: Calcium channel blockers nifedipine and diltiazem inhibit $\mathrm{Ca}^{2+}$ release from intracellular stores in neutrophils. J Biol Chem 1992, 267:|443-|448.

54. Tolloczko B, Tao FC, Zacour ME, Martin JG: Tyrosine kinasedependent calcium signaling in airway smooth muscle cells. Am J Physiol Lung Cell Mol Physiol 2000, 278:L I I 38-LI I45.

55. Small RC, Boyle JP, Duty S, Elliott KR, Foster RW, Watt AJ: Analysis of the relaxant effects of $\mathrm{AH} 21-132$ in guinea-pig isolated trachealis. $\mathrm{Br}$ J Pharmacol 1989, 97:। |65-1।73.

56. Smith PG, Garcia R, Kogerman L: Mechanical strain increases protein tyrosine phosphorylation in airway smooth muscle cells. Exp Cell Res 1998, 239:353-360.

57. Emala CW, Liu F, Hirshman CA: Gialpha but not gqalpha is linked to activation of p2I(ras) in human airway smooth muscle cells. Am J Physiol 1999, 276:L564-L570.

58. Hakonarson H, Grunstein MM: Regulation of second messengers associated with airway smooth muscle contraction and relaxation. Am J Respir Crit Care Med 1998, I 58:SII5-SI 22.

59. Hirshman CA, Emala CW: Actin reorganization in airway smooth muscle cells involves $\mathbf{G}_{q}$ and $\mathbf{G}_{i-2}$ activation of $\mathbf{R h o}$ Am J Physiol 1999, 277:L653-L66I.

60. Togashi H, Emala CW, Hall IP, Hirshman CA: Carbachol-induced actin reorganization involves $\mathbf{G}_{i}$ activation of $\mathbf{R h o}$ in human airway smooth muscle cells. Am J Physiol 1998, 274:L803-L809.

61. Gunst S], Tang DD: The contractile apparatus and mechanical properties of airway smooth muscle. Eur Respir J 2000, | 5:600-6 |6.

62. Madison JM, Ethier MF, Yamaguchi H: Refilling of caffeine-sensitive intracellular calcium stores in bovine airway smooth muscle cells. Am J Physiol 1998, 275:L852-L860.

63. Tang DD, Gunst SJ: Depletion of focal adhesion kinase by antisense depresses contractile activation of smooth muscle. Am J Physiol Cell Physiol 200I, 280:C874-C883.

64. Perez JF, Sanderson MJ: The contraction of smooth muscle cells of intrapulmonary arterioles is determined by the frequency of $\mathrm{Ca}^{2+}$ oscillations induced by $5-\mathbf{H T}$ and $\mathbf{K C l}$. I Gen Physiol 2005, I 25:555-567.

65. Perez JF, Sanderson MJ: The frequency of calcium oscillations induced by 5-HT, Ach and $\mathrm{KCl}$ determine the contraction of smooth muscle cells of intrapulmonary bronchioles. J Gen Physiol 2005, I 25:535-553.

66. Janssen LJ, Sims SM: $\mathbf{C a}^{2+}$-dependent $\mathbf{C l}$-current in canine tracheal smooth muscle cells. Am J Physiol 1995, 269:C 163-CI69.

67. ZhuGe R, Sims SM, Tuft RA, Fogarty KE, Walsh JV: Ca ${ }^{2+}$ sparks activate $\mathrm{K}^{+}$and $\mathrm{Cl}$-channels, resulting in spontaneous transient currents in guinea-pig tracheal myocytes. J Physiol 1998, 5 |3(Pt 3):7||-7|8

68. Wang $Y X$, Kotlikoff MI: Inactivation of calcium-activated chloride channels in smooth muscle by calcium/calmodulindependent protein kinase. Proc Natl Acad Sci USA 1997, 94:|4918-14923

69. Waniishi Y, Inoue R, Morita H, Teramoto N, Abe K, Ito Y: Cyclic GMP-dependent but G-kinase-independent inhibition of $\mathrm{Ca}^{2+}$-dependent $\mathrm{Cl}$-currents by $\mathrm{NO}$ donors in cat tracheal smooth muscle. J Physiol 1998, 5 I I (Pt 3):7|9-73I.

70. Janssen LJ, Sims SM: Acetylcholine activates non-selective cation and chloride conductances in canine and guinea-pig tracheal myocytes. J Physiol 1992, 453:197-218.

71. Janssen LJ, Sims SM: Histamine activates $\mathrm{Cl}$ - and $\mathrm{K}^{+}$currents in guinea-pig tracheal myocytes: convergence with muscarinic signalling pathway. I Physiol | 993, 465:66 |-677.

72. Oonuma $H$, Nakajima T, Nagata $T$, Iwasawa $K$, Wang $Y$, Hazama $H$, Morita $Y$, Yamamoto $K$, Nagai $R$, Omata $M$ : Endothelin-I is a potent activator of nonselective cation currents in human bronchial smooth muscle cells. Am J Respir Cell Mol Biol 2000, 23:213-22|.
73. Ahern GP, Laver DR: ATP inhibition and rectification of a $\mathbf{C a}^{2+}$ activated anion channel in sarcoplasmic reticulum of skeletal muscle. Biophys J 1998, 74:2335-235I.

74. Janssen LJ: Ionic mechanisms and $\mathbf{C a}^{2+}$ regulation in airway smooth muscle contraction: do the data contradict dogma? Am J Physiol Lung Cell Mol Physiol 2002, 282:LI I6I-LI I78.

75. Hirota S, Trimble N, Pertens E, Janssen LJ: Intracellular Cl-fluxes play a novel role in $\mathrm{Ca}^{2+}$-handling in airway smooth muscle. Am J Physiol Lung Cell Mol Physiol 2006.

76. Higashijima T, Ferguson KM, Sternweis PC: Regulation of hormone-sensitive GTP-dependent regulatory proteins by chloride. I Biol Chem 1987, 262:3597-3602.

77. lizuka K, Yoshii A, Samizo K, Tsukagoshi H, Ishizuka T, Dobashi K, Nakazawa T, Mori M: A major role for the rho-associated coiled coil forming protein kinase in G-protein-mediated $\mathrm{Ca}^{2+}$ sensitization through inhibition of myosin phosphatase in rabbit trachea. BrJ Pharmacol 1999, I 28:925-933.

78. Nakahara T, Moriuchi H, Yunoki M, Sakamato K, Ishii K: Y-27632 potentiates relaxant effects of beta 2 -adrenoceptor agonists in bovine tracheal smooth muscle. Eur J Pharmacol 2000, 389:103-106.

79. Yoshii A, lizuka K, Dobashi K, Horie T, Harada T, Nakazawa T, Mori $M$ : Relaxation of contracted rabbit tracheal and human bronchial smooth muscle by $\mathrm{Y}-27632$ through inhibition of $\mathrm{Ca}^{2+}$ sensitization. Am J Respir Cell Mol Biol 1999, 20: I I 90- I 200.

80. Hashimoto T, Nakano Y, Yamashita M, Fang YI, Ohata H, Momose K Role of Rho-associated protein kinase and histamine in lysophosphatidic acid-induced airway hyperresponsiveness in guinea pigs. Jpn J Pharmacol 2002, 88:256-26I.

81. Chiba Y, Takada Y, Sakai H, Takeyama H, Misawa M: Acetylcholineinduced smooth muscle contraction of intrapulmonary small bronchi is augmented in antigen-induced airway hyperresponsive rats. Jpn J Pharmacol 2000, 84:221-224.

82. Chiba Y, Takada Y, Miyamoto S, MitsuiSaito M, Karaki H, Misawa M: Augmented acetylcholine-induced, Rho-mediated $\mathrm{Ca}^{2+}$ sensitization of bronchial smooth muscle contraction in antigen-induced airway hyperresponsive rats. Br J Pharmacol 1999 , i 27:597-600.

83. Chiba Y, Sakai H, Misawa M: Augmented acetylcholine-induced translocation of RhoA in bronchial smooth muscle from antigen-induced airway hyperresponsive rats. Br J Pharmacol $200 \mathrm{I}$, I33:886-890.

84. Chiba $Y$, Misawa M: The role of RhoA-mediated $\mathbf{C a}^{2+}$ sensitization of bronchial smooth muscle contraction in airway hyperresponsiveness. I Smooth Muscle Res 2004, 40: I55-I 67.

85. Chiba Y, Sakai H, Wachi H, Sugitani H, Seyama Y, Misawa M: Upregulation of RhoA mRNA in bronchial smooth muscle of antigen-induced airway hyperresponsive rats. I Smooth Muscle Res 2003, 39:221-228

86. Sakai H, Otogoto S, Chiba Y, Abe K, Misawa M: TNF-alpha augments the expression of RhoA in the rat bronchus. I Smooth Muscle Res 2004, 40:25-34

87. Croxton TL, Lande B, Hirshman CA: Role of $\mathbf{G}$ proteins in agonist-induced $\mathrm{Ca}^{2+}$ sensitization of tracheal smooth muscle. Am J Physiol 1998, 275:L748-L755.

88. Janssen LJ, Tazzeo T, Zuo J, Pertens E, Keshavjee S: $\mathbf{K C l}$ evokes contraction of airway smooth muscle via activation of RhoA and Rho-kinase. Am J Physiol Lung Cell Mol Physiol 2004, 287:L852-L858.

89. Janssen LJ, Wattie J, Lu-Chao H, Tazzeo T: Muscarinic excitationcontraction coupling mechanisms in tracheal and bronchial smooth muscles. J Appl Physiol 2001, 91: I|42-II5I.

90. Rosenfeldt HM, Amrani Y, Watterson KR, Murthy KS, Panettieri RA Jr, Spiegel S: Sphingosine-I-phosphate stimulates contraction of human airway smooth muscle cells. FASEB J 2003, I 7:1789-1799.

91. Kobrinsky E, Schwartz E, Abernethy DR, Soldatov NM: Voltagegated mobility of the $\mathrm{Ca}^{2+}$ channel cytoplasmic tails and its regulatory role. J Biol Chem 2003, 278:502I-5028.

92. Soldatov NM: $\mathbf{C a}^{2+}$ channel moving tail: link between $\mathrm{Ca}^{2+}$ induced inactivation and $\mathbf{C a}^{2+}$ signal transduction. Trends Pharmacol Sci 2003, 24:167-17|

93. Kimura K, Ito M, Amano M, Chihara K, Fukata $Y$, Nakafuku M, Yamamori B, Feng J, Nakano T, Okawa K, Iwamatsu A, Kaibuchi K: Regulation of myosin phosphatase by Rho and Rho-associated kinase (Rho-kinase). Science 1996, 273:245-248. 
94. Kosako H, Yoshida T, Matsumura F, Ishizaki T, Narumiya S, Inagaki M: Rho-kinase/ROCK is involved in cytokinesis through the phosphorylation of myosin light chain and not ezrin/radixin/ moesin proteins at the cleavage furrow. Oncogene 2000, 1 9:6059-6064

95. Yamashiro S, Totsukawa G, Yamakita Y, Sasaki Y, Madaule P, Ishizaki T, Narumiya S, Matsumura F: Citron kinase, a Rho-dependent kinase, induces di-phosphorylation of regulatory light chain of myosin II. Mol Biol Cell 2003, I 4: I745-I756.

96. Matsui T, Maeda M, Doi Y, Yonemura S, Amano M, Kaibuchi K, Tsukita S, Tsukita S: Rho-kinase phosphorylates COOH-terminal threonines of ezrin/radixin/moesin (ERM) proteins and regulates their head-to-tail association. J Cell Biol 1998, I40:647-657.

97. Fukata Y, Kimura K, Oshiro N, Saya H, Matsuura Y, Kaibuchi K: Association of the myosin-binding subunit of myosin phosphatase and moesin: dual regulation of moesin phosphorylation by Rho-associated kinase and myosin phosphatase. I Cell Biol 1998, | 41:409-418.

98. Oshiro N, Fukata Y, Kaibuchi K: Phosphorylation of moesin by rho-associated kinase (Rho-kinase) plays a crucial role in the formation of microvilli-like structures. J Biol Chem 1998, 273:34663-34666.

99. Fukata $\mathrm{Y}$, Oshiro $\mathrm{N}$, Kaibuchi $\mathrm{K}$ : Activation of moesin and adducin by Rho-kinase downstream of Rho. Biophys Chem 1999, 82: $139-147$.

100. Izawa T, Fukata Y, Kimura T, Iwamatsu A, Dohi K, Kaibuchi K: Elongation factor-I alpha is a novel substrate of rho-associated kinase. Biochem Biophys Res Commun 2000, 278:72-78.

10I. Fukata Y, Oshiro N, Kinoshita N, Kawano Y, Matsuoka Y, Bennett V, Matsuura $Y$, Kaibuchi K: Phosphorylation of adducin by Rhokinase plays a crucial role in cell motility. J Cell Biol 1999, 145:347-36I.

102. Goto $H$, Kosako $H$, Inagaki M: Regulation of intermediate filament organization during cytokinesis: possible roles of Rhoassociated kinase. Microsc Res Tech 2000, 49: I73-I82.

103. Kosako H, Goto H, Yanagida M, Matsuzawa K, Fujita M, Tomono Y, Okigaki T, Odai H, Kaibuchi K, Inagaki M: Specific accumulation of Rho-associated kinase at the cleavage furrow during cytokinesis: cleavage furrow-specific phosphorylation of intermediate filaments. Oncogene 1999, I 8:2783-2788.

104. Goto H, Kosako H, Tanabe K, Yanagida M, Sakurai M, Amano M, Kaibuchi K, Inagaki M: Phosphorylation of vimentin by Rho-associated kinase at a unique amino-terminal site that is specifically phosphorylated during cytokinesis. J Biol Chem 1998, 273:11728-11736.

105. Maekawa M, Ishizaki T, Boku S, Watanabe N, Fujita A, Iwamatsu A, Obinata T, Ohashi K, Mizuno K, Narumiya S: Signaling from Rho to the actin cytoskeleton through protein kinases ROCK and LIM-kinase. Science 1999, 285:895-898.

106. Ohashi K, Nagata K, Maekawa M, Ishizaki T, Narumiya S, Mizuno K: Rho-associated kinase ROCK activates LIM-kinase I by phosphorylation at threonine $\mathbf{5 0 8}$ within the activation loop. J Biol Chem 2000, 275:3577-3582.

107. Landmesser U, Bahlmann F, Mueller M, Spiekermann S, Kirchhoff N, Schulz S, Manes C, Fischer D, de Groot K, Fliser D, Fauler G, Marz $W$, Drexler $\mathrm{H}$ : Simvastatin versus ezetimibe: pleiotropic and lipid-lowering effects on endothelial function in humans. Circulation 2005, I I I:2356-2363

108. Wassmann S, Faul A, Hennen B, Scheller B, Bohm M, Nickenig G: Rapid effect of 3-hydroxy-3-methylglutaryl coenzyme a reductase inhibition on coronary endothelial function. Circ Res 2003, 93:e98-103.

109. Gerthoffer WT, Gunst SJ: Focal adhesion and small heat shock proteins in the regulation of actin remodeling and contractility in smooth muscle. J Appl Physiol 2001, 91:963-972.

I 10. Mehta D, Tang DD, Wu MF, Atkinson S, Gunst S]: Role of Rho in $\mathrm{Ca}^{2+}$-insensitive contraction and paxillin tyrosine phosphorylation in smooth muscle. Am J Physiol Cell Physiol 2000, 279:C308-C318.

III. Tang DD, Gunst S]: Roles of focal adhesion kinase and paxillin in the mechanosensitive regulation of myosin phosphorylation in smooth muscle. J Appl Physiol 200 I, 9 I: | $452-1459$.

I 12. Mitzner W: Airway smooth muscle: the appendix of the lung. Am J Respir Crit Care Med 2004, I 69:787-790.
I13. Cox G, Miller JD, McWilliams A, Fitzgerald JM, Lam S: Bronchial thermoplasty for asthma. Am J Respir Crit Care Med 2006, I 73:965-969.

II4. Miller JD, Cox G, Vincic L, Lombard CM, Loomas BE, Danek C]: A prospective feasibility study of bronchial thermoplasty in the human airway. Chest 2005, I 27:1999-2006.

II5. Mitchell HW, Sparrow MP: The relevance of pharmacological dose - response curves to airway narrowing. Trends Pharmacol Sci 1989, I0:488-49I.

I 16. Gump A, Haughney L, Fredberg J: Relaxation of activated airway smooth muscle: relative potency of isoproterenol vs. tidal stretch. I Appl Physiol 200I, 90:2306-2310.

I 17. Kuo KH, Wang L, Pare PD, Ford LE, Seow CY: Myosin thick filament lability induced by mechanical strain in airway smooth muscle. J Appl Physiol 2001, 90:181 |-1816.

I 18. Waters CM, Sporn PH, Liu M, Fredberg J): Cellular biomechanics in the lung. Am J Physiol Lung Cell Mol Physiol 2002, 283:L503-L509.

Publish with Bio Med Central and every scientist can read your work free of charge

"BioMed Central will be the most significant development for disseminating the results of biomedical research in our lifetime. "

Sir Paul Nurse, Cancer Research UK

Your research papers will be:

- available free of charge to the entire biomedical community

- peer reviewed and published immediately upon acceptance

- cited in PubMed and archived on PubMed Central

- yours - you keep the copyright

BiolMedcentral 